\title{
The Mediterranean fruit fly (Ceratitis capitata) in Iran: genetic diversity and comparison with other countries
}

\author{
M. Rajabiyan, M. Shayanmehr, M. Mohammadi Sharif \\ Department of Plant Protection, Sari University of Agricultural Sciences and Natural \\ Resources, Sari, Mazandaran, Iran
}

\begin{abstract}
The Mediterranean fruit fly, Ceratitis capitata (Wiedemann) is an economically important pest on fruits all over the world. The origin of this fly is thought to be from Africa, but it has recently expanded its distribution in many geographic regions including Iran. Due to the wide spread of this pest in Iran and its serious damage to fruit on trees, including citrus orchards of northern Iran, the present study was conducted firstly to investigate genetic diversity within populations of C. capitata based on the sequences of three mitochondrial DNA (mtDNA) genes including cytochrome $\mathrm{C}$ oxidase I (COI), NAHD dehydrogenase subunits 4 and 5 (ND4 and ND5) and secondly to compare the Iranian haplotypes with those found in other countries. Results of this study indicated low levels of genetic diversity (four, four and three haplotypes among different populations of this pest, respectively for the COI, ND4 and ND5 genes) in northern Iranian populations. The genetic similarity and very low levels of genetic diversity of northern Iranian populations suggest that the pest colonisation occurred relatively recently. In addition, haplotypes of Mazandaran province are
\end{abstract}

Correspondence: Masoumeh Shayanmehr, Department of Plant Protection, Faculty of Crop Sciences, Sari University of Agricultural Sciences and Natural Resources, Sari P.0. Box: 578, Mazandaran, Iran.

Telefax: +981513822567 .

E-mail: shayanm30@yahoo.com

Key words: Mediterranean fruit fly; mitochondrial DNA; genetic variation; haplotypes; northern Iran.

Acknowledgements: we would like to thank the Sari Agricultural Sciences and Natural Resources University for financial support of this research. Also we are appreciated to Dr. Antonio Carapelli from Italy for kind help during the work.

Received for publication: 16 May 2014.

Revision received: 22 October 2014.

Accepted for publication: 16 January 2015.

(C) Copyright M. Rajabiyan et al., 2015

Licensee PAGEPress, Italy

Journal of Entomological and Acarological Research 2015; 47:4055

doi:10.4081/jear.2015.4055

This article is distributed under the terms of the Creative Commons Attribution Noncommercial License (by-nc 3.0) which permits any noncommercial use, distribution, and reproduction in any medium, provided the original author(s) and source are credited. similar to haplotypes of those countries that have recently been infected by this pest.

\section{Introduction}

The Mediterranean fruit fly, Ceratitis capitata (Wiedemann) (Diptera: Tephritidae) is one of the world's most economically important pest species of fruit trees (Sheppard et al., 1992). This pest has spread rapidly from its putative source area in central Africa to north and South Africa in 1842 (Hagen et al., 1981). The medfly is a major reason for direct economic losses in fruit production, and eradication programs are routinely carried out in several countries where this pest causes considerable damage (Dowell \& Krass, 1992). For these reasons, several research projects have focused on the genetic diversity of the medfly populations in many regions worldwide (Sheppard et al., 1992; Elfekih et al., 2010a, 2010b). Different kinds of genetic markers have been used for analysis of diversity in medfly populations (Reyes \& Ochando, 2004).

C. capitata was originally recorded from Iran in 1958 (southern Iran), and subsequently in 1980 (northern Iran) (Mirsardo et al., 2010). Given the wide distribution, high invasiveness and serious economic impact of this pest on fruit production, it is crucial to conduct a survey of the genetic diversity of medfly populations where this pest occurs (Elfekih et al., 2010b). Previous studies used several markers including mitochondrial DNA, which proved to be very useful given its haploid nature and maternal inheritance as well as its lack of recombination (Hewitt, 2004).

Despite the extensive research work done on medfly genetic diversity in several areas worldwide (Reyes \& Ochando, 2004; Barr, 2009; Elfekih et al., 2010b), very limited information is available on the genetic variability of medfly populations in Iran.

The main objective of the present study is to characterise the genetic diversity among medfly populations in Iran using mitochondrial DNA markers. The sequences of mtDNAs including the cytochrome oxidase I (COI), NADH dehydrogenase subunits 4 and 5 (NADH4 and $N A D H 5$ ) genes are used for characterisation of genetic diversity in medfly populations in different areas of Mazandaran province (northern Iran). Furthermore, the sequences of mitochondrial DNA from other countries, recorded in National Centre for Biotechnology Information (NCBI), were employed for comparisons.

\section{Materials and methods}

Adult specimens of $C$. capitata were collected from different areas of Mazandaran province in northern Iran (Figure 1). The specimens 
were captured using pheromone traps (Xlure-cec), placed in citrus orchards. All samples were preserved in $90 \%$ ethanol (Table 1).

Total genomic DNA was extracted from individual specimens using the DNeasy Blood and Tissue DNA extraction Kit (Qiagen, Hilden, Germany). DNA was extracted by placing single individuals in an Eppendorf tube and the wings were removed.

The extracted DNA from medfly specimens was amplified using three pair primers (Table 2). The COI primer pair amplifies a $631 \mathrm{bp}$ fragment of the COI gene. Amplifications were performed in $25 \mu \mathrm{L}$ microtubes containing $1 \mu \mathrm{L} \mathrm{MgCl}_{2}, 1.5 \mu \mathrm{L}$ primers $(10 \mathrm{pm} / \mu \mathrm{L}), 0.5 \mu \mathrm{L}$ dNTPs, $2.5 \mu \mathrm{L}$ polymerase chain reaction (PCR) buffer, $0.2 \mathrm{Taq}$

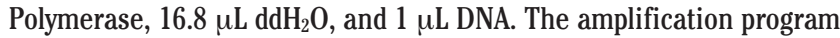
has an initial denaturation step of $5 \mathrm{~min}$ at $94^{\circ} \mathrm{C}$, followed by 35 cycles of $60 \mathrm{~s}$ in $94^{\circ} \mathrm{C}, 60 \mathrm{~s}$ in $43^{\circ} \mathrm{C}, 90 \mathrm{~s}$ at $72^{\circ} \mathrm{C}$, and a final extension of 7 min at $72^{\circ} \mathrm{C}$. The ND4 and ND5 primer pairs are used to amplify a 350 and $950 \mathrm{bp}$ fragment of the $N A D H 4$ and $N A D H 5$ genes, respectively. The

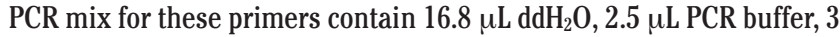
$\mu \mathrm{L} \mathrm{MgCl}_{2}, 0.5 \mu \mathrm{L}$ dNTPs, $0.5 \mu \mathrm{L}$ primers, $1 \mu \mathrm{L}$ DNA and $0.2 \mu \mathrm{L}$ Taq

Table 1. Information on sampling sites in Mazadaran province.

\begin{tabular}{|c|c|c|c|c|c|}
\hline \multirow{2}{*}{$\begin{array}{l}\text { Sampling site } \\
\text { Locality }\end{array}$} & \multicolumn{2}{|c|}{ Coordinate } & \multicolumn{3}{|c|}{ Number of individuals from each gene } \\
\hline & Longitude (N) & Latitude (E) & $\mathrm{COI}$ & ND4 & ND5 \\
\hline Amol & $36^{\circ} 28^{\prime} 14^{\prime \prime}$ & $52^{\circ} 21^{\prime} 47^{\prime \prime}$ & 1 & 2 & 3 \\
\hline Behshahr & $36^{\circ} 41^{\prime} 39^{\prime \prime}$ & $53^{\circ} 32^{\prime} 33^{\prime \prime}$ & 1 & 1 & 3 \\
\hline Tonekabon & $36^{\circ} 48^{\prime} 31^{\prime \prime}$ & $50^{\circ} 52^{\prime} 54^{\prime \prime}$ & 1 & 1 & 2 \\
\hline Juybar & $36^{\circ} 38^{\prime} 17^{\prime \prime}$ & $52^{\circ} 54^{\prime} 42^{\prime \prime}$ & 1 & 2 & 3 \\
\hline Sari & $36^{\circ} 34^{\prime} 4^{\prime \prime}$ & $53^{\circ} 03^{\prime} 31^{\prime \prime}$ & 1 & 2 & 3 \\
\hline Qaemshahr & $36^{\circ} 27^{\prime} 47^{\prime \prime}$ & $52^{\circ} 51^{\prime} 36^{\prime \prime}$ & 1 & 2 & 3 \\
\hline Mahmudabad & $36^{\circ} 36^{\prime} 47^{\prime \prime}$ & $53^{\circ} 51^{\prime} 36^{\prime \prime}$ & 0 & 1 & 3 \\
\hline Neka & $36^{\circ} 39^{\prime} 5^{\prime \prime}$ & $53^{\circ} 17^{\prime} 48^{\prime \prime}$ & 1 & 2 & 3 \\
\hline Nur & $36^{\circ} 33^{\prime} 45^{\prime \prime}$ & $52^{\circ} 01^{\prime} 54^{\prime \prime}$ & 1 & 2 & 3 \\
\hline
\end{tabular}

Table 2. Name and sequence of mtDNA primers used for polymerase chain reaction reaction.

\begin{tabular}{|c|c|c|c|c|}
\hline Primer & Sequence of primer (5 -3 ) & Gene & Size (bp) & Reference \\
\hline $\begin{array}{l}\text { LCO1490 } \\
\text { HCO2198 }\end{array}$ & $\begin{array}{l}\text { GGTCAACAAATCATAAAGATATTGG } \\
\text { TAAACTTCAGGGTGACCAAAAAATC }\end{array}$ & $\mathrm{COI}$ & 360 & Folmer et al., 1994 \\
\hline $\begin{array}{l}\text { N-4-J-8883 } \\
\text { N-4-N-9243 }\end{array}$ & $\begin{array}{l}\text { TAATAATCCATATCCTCCTA } \\
\text { TTAGTTTTAACATTTAGAAG }\end{array}$ & ND4 & 350 & Elfekih et al.,2010a \\
\hline $\begin{array}{l}\text { N-5-J-7991 } \\
\text { N-4-N-8916 }\end{array}$ & $\begin{array}{l}\text { TAATAAACTCATTCAATCAA } \\
\text { ATAGAAGCTCCTGTATCTGG }\end{array}$ & ND5 & 950 & Elfekih et al., 2010b \\
\hline
\end{tabular}

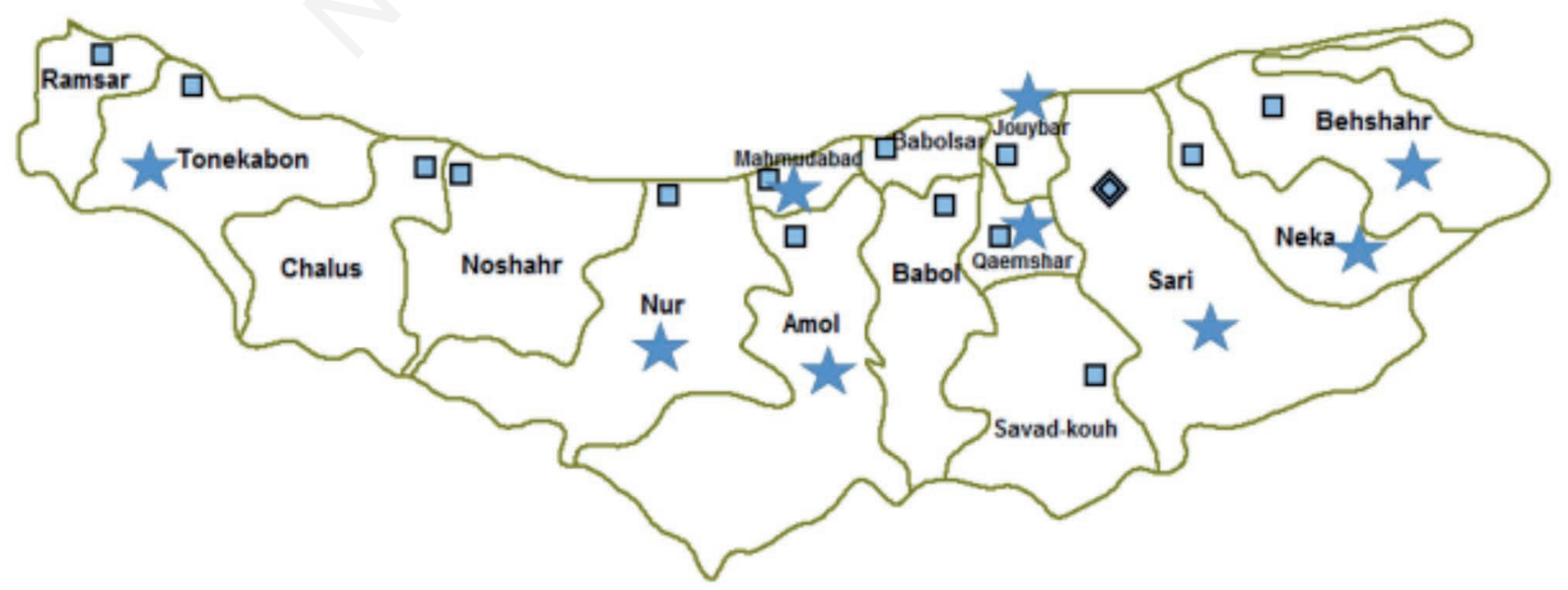

Figure 1. Map of Mazandaran province (northern Iran) indicating the sampling localities. 
Polymerase. The amplification program has an initial denaturation step of $2 \mathrm{~min}$ at $94^{\circ} \mathrm{C}$, followed by 40 cycles of $30 \mathrm{~s}$ in $94^{\circ} \mathrm{C}, 30 \mathrm{~s}$ in $46^{\circ} \mathrm{C}$, $2 \mathrm{~min}$ at $66^{\circ} \mathrm{C}$, and a final extension of $2 \mathrm{~min}$ at $72^{\circ} \mathrm{C}$ (Elfekih et al., 2010a). Amplification products $(5 \mu \mathrm{L})$ were visualised after electrophoresis in 2\% agarose gels in TAE buffer (24.2 gr Tris Acetic acid 71 $m L$ EDTA $10 \mathrm{~mL} d d H 2 O 60 \mathrm{~mL}$ ) with the 1-log ladder as a molecular weight marker. Purification and sequencing of PCR products for forward primer from individual specimens performed by Takapu-zist Company. The accession numbers in GenBank for COI sequences of $C$. capitata obtained here are KM660641-KM660652.

A Blast search of GenBank sequences using the sequence obtained from the PCR product was conducted through the NCBI website (http://www.ncbi.nlm.gov). Sequences were aligned using Clustal X with defaults/parameters (Thompson et al., 1997). Phylogenetic trees were constructed using the maximum likelihood algorithm in MEGA5 (Tamura et al., 2011). Numbers of haplotypes and numbers of mutations were identified using DnaSP (Librado \& Rozas, 2009).
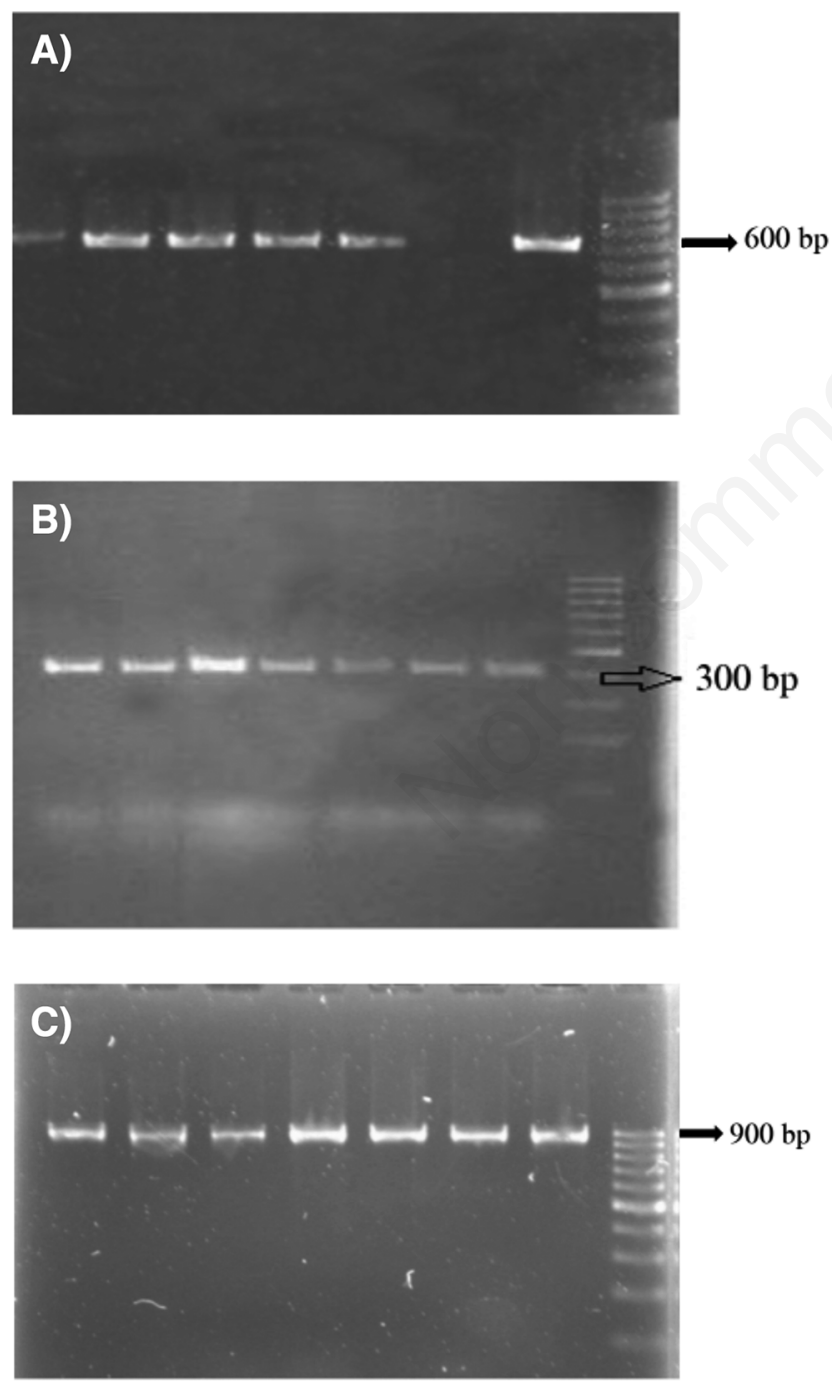

Figure 2. A) $C O I-$; B) ND4- ; C) ND5-DNA fragment amplified of Mediterranean fruit fly from different cities of Mazandaran province.

\section{Results}

Intraspecific genetic variation was investigated using molecular marker obtained from COI, ND4 and ND5 sequences in nine populations of the Mediterranean fruit fly, $C$. capitata from northern Iran. In sum, genetic relationships were constructed for mitochondrial DNA sequences generated from 48 individuals. The total length of COI, ND4 and ND5 products were 650, 372 and $950 \mathrm{bp}$, respectively (Figure 2). In order to eliminate the errors due to sequencing artifacts, we considered only fragments of $631 \mathrm{bp}$ of COI, $350 \mathrm{bp}$ of ND4 and $899 \mathrm{bp}$ of ND5 for all sequences by deleting the beginning and end of the sequences.

The number of haplotypes, number of mutations and average frequency of bases for the different markers are shown in Table 3. The A$\mathrm{T}$ rich sequences were observed in nucleotide composition, which is a pattern that has been repeatedly seen in the mtDNA of Dipteran species (Bajpai \& Tewari, 2010).

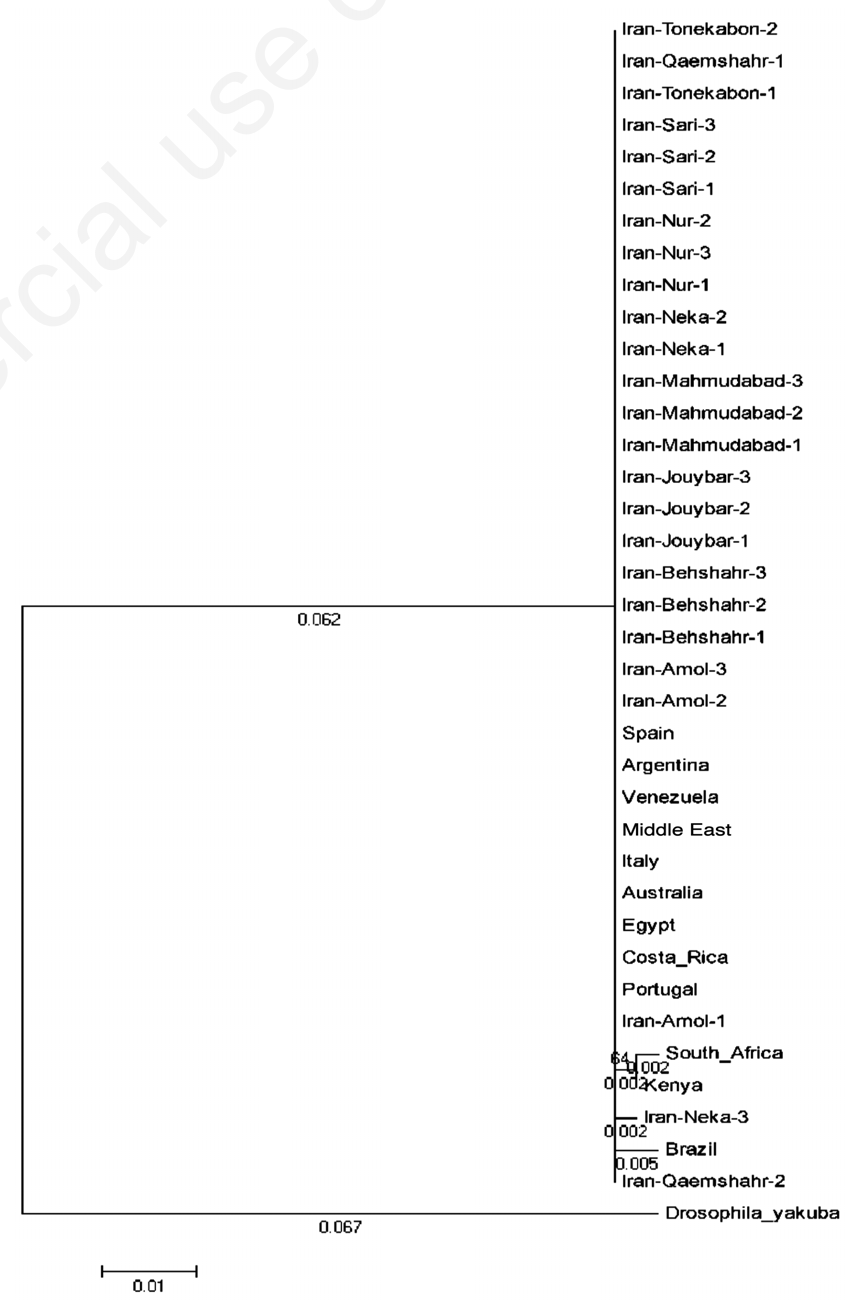

Figure 3. Maximum likelihood tree of 25 specimens of Ceratitis capitata from Mazandaran province and twelve other countries for COI, calculated in MEGA5. Drosophila yakuba used as outgroup. Numbers above the branches indicate the bootstrap values for nodes (1000 replications). 
Genetic distances were calculated among the nine populations using the binary data obtained for each primer pair. Very low genetic distance values were found, indicating a high genetic similarity among the derived populations in general. The largest genetic distance values are observed between Neka ${ }_{1}$ and $\mathrm{Neka}_{3}(0.008)$ for COI, Behshahr and $\mathrm{Neka}_{2}(0.022)$ for ND5, Qaemshahr and Sari (0.002) for ND5.

Phylogenetic trees were constructed using likelihood based (ML from 1000 bootstrap replicates) algorithms in MEGA5 (Tamura et al., 2011). A set of medfly mitochondrial DNA sequences, available on Genbank, was used in order to compare the Iranian populations with medfly populations from other geographical regions (Figures 3-5). The species, Drosophila yakuba (Diptera: Drosophilidae) was used as an out-group for construction of phylogenetic trees. Additionally, statistical parsimony (Templeton, 2004) implemented in the TCS software (Clement et al., 2000) with a 150-step connection limit, was used to construct parsimonious networks of COI haplotypes for populations of $C$. capitata.

The phylogenetic tree (Figure 3) shows that different populations of the medfly are similar in $\mathrm{COI}$ gene sequences in that they are placed in one branch separated from the out-group. Three populations, including Neka-1, Neka-3 and Tonekabon-2, appear to be a little bit different from the others. The presence of four haplotypes among the nine populations of the medfly is confirmed by the TCS plot as well for COI gene (Figure 6). These medfly populations have a bias toward haplotype A. The phylogenetic tree also affirms a very close genetic similarity among populations of medfly in northern Iran and some other countries such Spain, Middle East, and Venezuela. However, populations of South Africa and Kenya show less similarity with the population in northern Iran.

The phylogenetic tree constructed for the ND4 gene (Figure 4) shows populations of medfly from different cities are genetically similar to each other. Also the maximum likelihood tree shows the medfly populations come from Middle East and Tunisia are relatively close to Iranian population. But in compare to the phylogenetic tree constructed by $\mathrm{COI}$ gene Middle East population showed a bit different from Iranian population.

The phylogenetic tree constructed based on ND5 sequences (Figure 5) also reveals genetic similarity among the populations of northern Iran. Populations of Neka, Behshahr, jouybar and Tonekabon are mostly close to each other and form one haplotype. Such genetic similarity is also repeated between populations of Nur, Sari and Amol. The populations of the other countries (USA and Argentina) are closely related to the populations of northern Iran. However Tunisia population showed again a bit deviation from others.

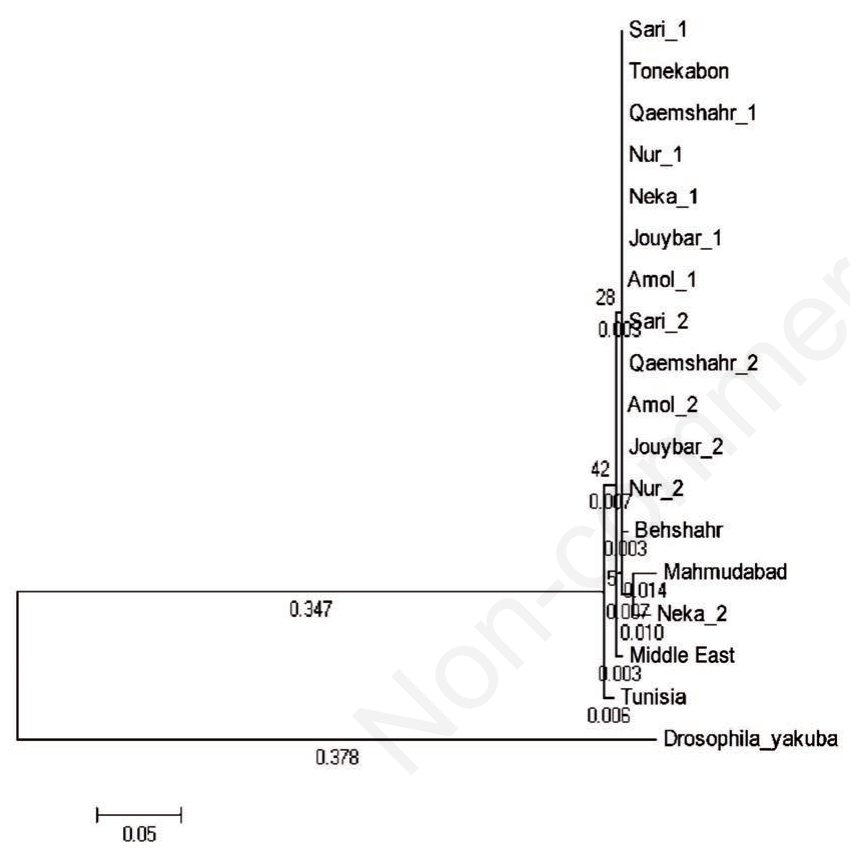

Figure 4. Maximum likelihood tree of sequences of 15 specimens of Ceratitis capitata from Mazandaran province and two other countries for ND4, with Drosophila yakuba as an out-group, calculated in MEGA5. Numbers indicate bootstrap values for nodes (1000 replications).
Figure 5. Maximum likelihood tree of sequences of 8 specimens of Ceratitis capitata from Mazandaran province and three other countries for ND5, with Drosophila yakuba as an out-group, calculated in MEGA5. Numbers indicate bootstrap values for nodes (1000 replications).

Table 3. The haplotypes of medfly populations according to sequences of the COI, ND4 and ND5 genes.

\begin{tabular}{lccccccc} 
& No. of haplotypes & No. of mutations & \multicolumn{4}{c}{ Average frequency of bases } \\
& & & A (\%) & T (\%) & C (\%) \\
COI & 4 & 6 & 28.7 & 39.3 & 16 & 16 \\
ND4 & 4 & 10 & 47.1 & 33 & 10.9 & 8.9 \\
\hline ND5 & 3 & 3 & 44.2 & 31.9 & 16.1 & 7.8 \\
\hline
\end{tabular}




\section{Discussion and conclusions}

DNA markers, such as those derived from nuclear genes, RAPDs and intron sequences, microsatellites, as well as those derived from mitochondrial DNA, have been used previously to study Mediterranean fruit fly populations (Elfekih et al., 2010b). Despite the wide spread of the $C$. capitata in northern Iran, no research has been done on previously on genetic diversity and evolutionary relationships of different populations of this pest in Iran.

According to Nei's estimates (1975) of the genetic distance ranges for local race of a species, low genetic distances among populations of different areas show genetically close relationships among them (Menezes, 1990). The low genetic distances found among populations of the medfly in Mazandaran province in this study indicate that these populations are genetically similar and that colonisation in citrus orchards by this pest took place once and relatively recently. The similarity among the medfly populations can be for different reasons. One reason could be the close distance of cities in Mazandaran province. Secondly, the spaces between the sampling localities have been filled with vast citrus orchards. Also the products of the orchards are exchanged between the cities, and transmission of infested fruit is one of the most important paths for distribution of the medfly in northern Iran (Mirsardo et al., 2010).

High genetic diversity is generally used as evidence that a species is native, or that it has been established for a long period of time (Solorzano et al., 2010). According to the haplotype diversity calculated in this study, it can be concluded that in northern Iran the medfly has not been present for a long time. Also, it is a new pest recorded for the first time in 1980 in northern Iran. Additionally, according to the assumptions of Malacrida et al., C. capitata populations can be divided into three main
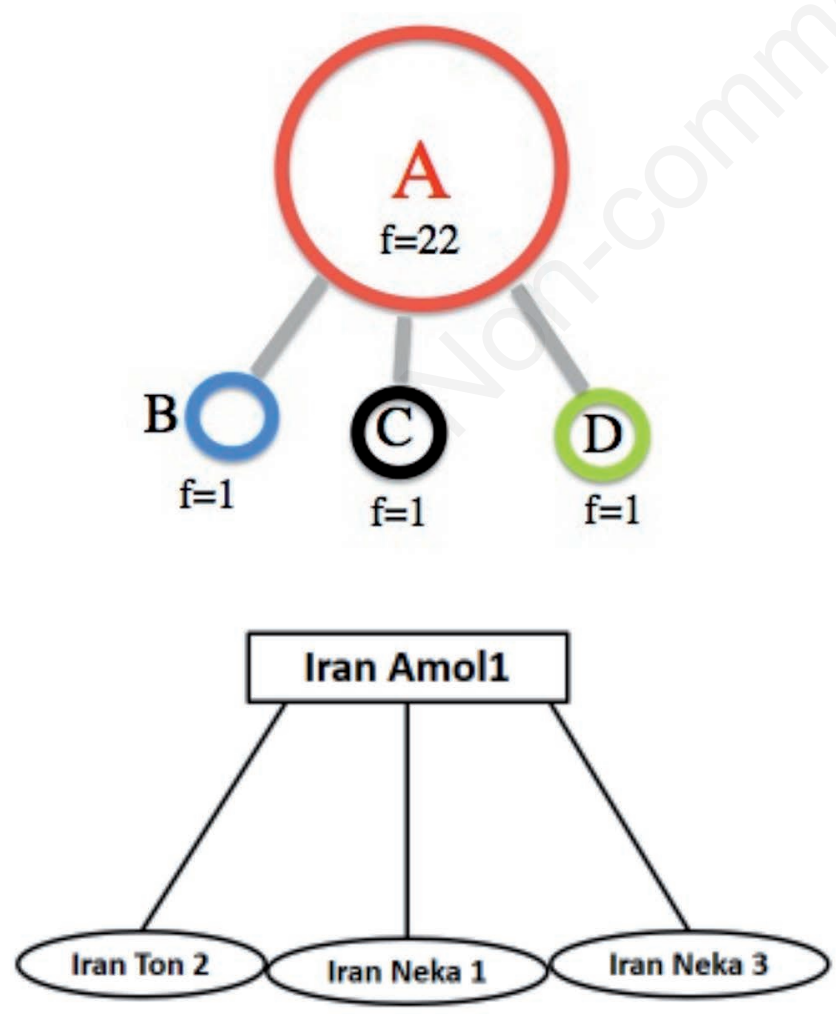

Figure 6. Reconstructed TCS plot of 4 cytochrome COI haplotypes of Ceratitis capitata; A to B-C-D = one substitution. categories according to their colonisation pattern: ancestral, ancient and new populations, corresponding to populations from Africa, the Mediterranean basin and America, respectively (Reyes \& Ochando, 2004). Finding of this study indicated there are few haplotypes in medfly population in Mazndaran province, so the population of medfly in northern Iran can be placed in the third category of Malacrida's classification. In other words, the colonisation of the pest has happened more recently and the pest has not had enough time for genetic divergence (Reyes \& Ochando, 2004). The phylogenic trees for COI gene sequences also confirm Malacrida's classification very well. The population from Africa (Kenya and South Africa) showed older colonisation than populations from Europe such as Spain and Italy, Middle East countries and even countries of the Americas such as Argentina and Venezuela. The close relations of the population of Iran with other countries show short history of existence of the medfly in these countries.

The phylogenic tree for ND4 showed also the African population (Tunisia) colonised older than Middle East countries such as Iran. Low genetic diversity in populations from Middle East (constructed by COI and ND4) indicated recent colonisation of pest in this area. The phylogenetic tree for ND5 also indicated older colonisation in Tunisia (African population) than American and Iranian populations.

The results of this study indicate that genetic analyses based on the use mitochondrial genes can provide useful tools for unravelling genetic and phylogenetic relationships in $C$. capitata populations in northern Iran. The variability identified by the direct analysis of such sequences will allow for answering a range of questions relevant to pest population dynamics such as the origin of new infestations, the relationships of existing populations and will allow pest management controls to be examined in greater detail than had been possible previously.

\section{References}

BAJPAI N., TEWARI R.R., 2010 - Mitochondrial DNA sequence-based phylogenetic relationship among flesh flies of the genus Sarcophaga (Sarcophagidae: Diptera). - Genetics 89: 51-54.

BARR N.B., 2009 - Pathway analysis of Ceratitis capitata (Diptera: Tephritidae) using mitochondrial DNA. - J. Econ. Entomol. 102: 401-402.

CLEMENT M., POSADA D., CRANDALL K.A., 2000 - TCS: a computer program to estimate gene genealogies. - Mol. Ecol. 9: 1657-1659.

DOWELL R.V., KRASS C. J., 1992 - Exotic pests pose growing problem for California. - Calif. Agr. 46: 6-12.

ELFEKIH S., HAYMER D.S., MAKNI M., 2010a - Detection of novel mitochondrial haplotype variants in populations of the Mediterranean fruit fly, Ceratitis capitata, from Tunisia, Israel and Morocco. - J. Appl. Entomol. 134: 647-651.

ELFEKIH S., HAYMER D.S., MAKNI M., 2010b - Genetic diversity of survey of ND5 mitochondrial patterns in Ceratitis capitata (Diptera: Tephritidae) populations from Tunisia. - Ann. Entomol. Soc. Fr. 46: 464-470.

FOLMER 0., BLACK M., HOEH W., LUTZ R., VRIJENHOEK R., 1994 DNA primers for amplification of mitochondrial cytochrome $c$ oxidase subunit I from diverse metazoan invertebrates. - Mol. Mar. Biol. Biotech. 3: 294-299.

HAGEN K.S., WILLIAM W.W., TASSAN R.L., 1981 - Mediterranean fruit fly: the worst may be yet to come. - Calif. Agr. 35: 5-7.

HEWITT G.M., 2004 - The structure of biodiversity-insights from molecular phylogeography. - Front. Zool. 1: 1-16.

LIBRAD0 P., R0ZAS J., 2009 - DnaSP v5: A software for comprehensive analysis of DNA polymorphism data. - Bioinformatics. 25: 1451-1452.

MALACRIDA A., GASPERI G., ZACHAROPOULOU A., TORTI C., FRANCOS E., MILANI R., 1992 - Evidence for a genetic duplication 
involving alcohol dehydrogenase genes in Ceratitis capitata. Biochem. - Genet. 30: 35-48.

MENEZES M.R., 1990 - Genetic distance and phylogenetic relationship. - Biol. Educat. 7: 297-303.

MIRSARDO0 S., MAFI-PASHAKOLAEI S.A., BARARI H., 2010 - Preliminary investigation on the geographical distribution of Mediterranean fruit fly, Ceratitis capitata (Wiedemann) (Dip., Tephritidae), in Mazandaran province, Iran. - J. Entomol. 2: 143-154. [In Farsi]

REYES A., OCHANDO D., 2004 - Mitochondrial DNA variation in Spanish populations of Ceratitis capitata (Wiedmann) (Tephritidae) and the colonisation process. - J. Appl. Ecol. 128: 358-364.

SHEPPARD W.S., STECK G.J., MCPHERON B.A., 1992 - Geographic populations of the medfly may be differentiated by mitochondrial DNA variation. - Experientia. 48: 1010-1013.
SOLORZANO C.D., SZALANSKI A.L., OWENS C.B., STEELMAN C.D., 2010 - Genetic diversity of Aedes vexans (Diptera, Culicidae) from New Orleans: pre- and post-Katrina. - Biochem. Genet. 48: 711-726.

TAMURA K., PETERSON D., PETERSON N., STECHER G., NEI M., KUMAR S., 2011 - MEGA5: molecular evolutionary genetics analysis using maximum likelihood, evolutionary distance, and maximum parsimony methods. - Mol. Biol. Evol. 28: 2731-2739.

TEMPLETON A.R., 2004 - Statistical phylogeography: methods of evaluating and minimising inference errors. - Mol. Ecol. 13: 789-809.

THOMPSON J.D., GIBSON T.J., PLEWNIAK F., JEANMOUGIN F., HIGGINS D.G., 1997 - The ClustalX windows interface: flexible strategies for multiple sequence alignment aided by quality analysis tools. - Nucleic. Acids. Res. 24: 4876-4882. 